\title{
The Territorial Inequalities In The Location Of The Foreign Direct Investment In The 90s: The Spanish Case
}

Raquel Díaz Vázquez, (E-mail: rdiaz@uvigo.es), Universidad de Vigo, Spain

\begin{abstract}
One of the main characteristics on the world economy during the second half of the eighties was the boom registered by the international investment, in particular, going to the Spanish economy. But the nineties were also characterised by the consolidation of these Foreign Direct Investment (FDI) inflows. In addition, the UNCTAD, in their World Investment Report (WIR) 2001, alert about a pattern of concentration of this FDI in the more developed countries in the last years that it is pushing to a concentration within a national environment in the more developed regions too. So, inside this context of concentration of the FDI in the international environment, and considering that the Spanish economy was one of the most important destinations for the FDI, the present paper wants to analyse if this same behaviour pattern of FDI is verified within the Spanish economy. The data will show that the geographical concentration of the FDI in the more developed regions exists and that is increasing along the time. A new strategy based on the relocation of foreign capital is generated from the international economic crisis. But the Spanish economy and, very in particular, the Madrid's community, they have never stopped to be attractive for the foreign investor. Even, the concentration of the foreign capital in this region is intensified along the time, harming the less developed regions of the Spanish economy. So, this paper wants to get the attention on this high degree of concentration of this foreign capital in the Spanish economy in terms of other macroeconomic variables, as the GDP or the GFCF. As result, a very important presence of foreign capital in the more developed areas is verified. And wide differences with regard to the remaining regions are shown.
\end{abstract}

